\title{
Epidemiology and costs of multiple sclerosis in Switzerland: an analysis of health-care claims data, $20 I I-20 I 5$
}

\section{Eva Blozik ${ }^{1-3}$ \\ Roland Rapold' \\ Klaus Eichler ${ }^{4}$ \\ Oliver Reich'}

'Department of Health Sciences, Helsana Group, Zürich, Switzerland; ${ }^{2}$ Institute of General Practice, University Medical Center HamburgEppendorf, Hamburg, Germany; ${ }^{3}$ Division of General Practice, University Medical Center Freiburg, Freiburg, Germany; ${ }^{4}$ Winterthur Institute of Health Economics, Zurich University of Applied Sciences, Winterthur, Switzerland
Correspondence: Eva Blozik Department of Health Sciences, Helsana Group, Post Box CH-808I, Zürich, Switzerland

$\mathrm{Tel}+4 \mathrm{I} 58340$ IIII

Fax +4I 583400100

Email eva.blozik@helsana.ch
This article was published in the following Dove Press journal:

Neuropsychiatric Disease and Treatment

I November 2017

Number of times this article has been viewed

Background: Medical therapy for multiple sclerosis (MS) is expensive. Quantifying the burden of MS is fundamental for health-care planning and the allocation of resources for the management of MS. This study provides current national estimates of prevalence, incidence, mortality, and costs of MS in Switzerland using claims data between 2011 and 2015.

Methods: We analyzed health insurance claims of adult persons enrolled with a large health insurance group covering about 13\% of the Swiss population between 2011 and 2015. The identification of patients with MS was based on prescription data of MS-specific medication using the Anatomical Therapeutic Chemical Classification system as proxy for clinical diagnosis. We estimated prevalence, mortality, and costs of basic health insurance between 2011 and 2015. Furthermore, incidence of MS was calculated for 2015. All results were weighted with census data to achieve an extrapolation to the Swiss general population level. Cost of illness was estimated as direct medical cost from the perspective of a Swiss health insurance using multivariate linear regression analysis.

Results: Of the 943,639 subjects in the year 2015, 1,606 were identified as MS patients resulting in a prevalence of 190 per 100,000 (95\% CI: 180-190 per 100,000). Incidence was 16 per 100,000 (95\% CI: 13-19 per 100,000). According to regression analysis, the total cost of illness for basic mandatory health insurance was 26,710 Swiss Francs (CHF) (95\% CI: 26,100-27,300) per person per year with the cost of medication being almost identical 26,960 CHF (95\% CI: 26,170-27,800).

Conclusions: MS affects 10,000-15,000 persons in Switzerland, and the prevalence has increased over the last 22 years. These persons have high need and demand for health care. High costs are primarily due to expenses for medication. Given the imbalance of MS medication therapy from the perspective of basic health insurance on the disposable resources, it is crucial to increase transparency related to the volume, type, and allocation of expenses.

Keywords: health insurance, Switzerland, medication, prescription, management, resources

\section{Background}

Multiple sclerosis (MS) is a chronic, so far incurable neurodegenerative disease often with an unpredictable course. ${ }^{1} \mathrm{MS}$ is associated with a broad spectrum of symptoms such as loss of bladder and bowel control, cognitive disorders, or psychological and psychiatric problems. ${ }^{2} \mathrm{MS}$ causes both utilization of health-care services and a decrease of labor capacity. ${ }^{3-5}$ It is estimated that more than 2 million persons worldwide suffer from MS which is one of the most common causes of neurological disability in young adults. ${ }^{6}$

Costs for care of patients with MS is highly correlated with disease severity. ${ }^{7,8}$ Costs of drugs have been shown to be main cost drivers in MS patients. ${ }^{9}$ New and promising therapies are being developed which, in turn, are associated with high costs in addition to existing therapies. ${ }^{10}$ Although there is still uncertainty related to comparative 
effectiveness of the different MS drugs, ${ }^{11,12}$ cost of fingolimod, for example, an immunosuppressive agent for the therapy of relapsing remitting MS increased in Switzerland by $750 \%$ from 2011 to 2014 indicating high dynamics in the use of MS medication. ${ }^{13}$ Measures of prevalence and incidence help to monitor disease burden in the population and are a basis for health-care planning and the allocation of resources for the management of MS, especially given the high costs associated with these new therapies. ${ }^{14}$

Previous surveys evaluated prevalence of MS in Switzerland. However, due to the methodological limitations of surveys, these results may be subject to sample selection bias, nonresponse, and inaccurate recall. In part, these data are quite outdated. ${ }^{15,16}$ In addition, to our knowledge, there are no incidence data for MS in Switzerland. With respect to costs of MS, one previous study published in 2006 was done in the Swiss health-care system. ${ }^{7}$ However, the expensive therapeutic innovations that have been established in recent years are likely to have impacted costs of MS in Switzerland. In the absence of other reliable data sources on MS, the analysis of health-care claims data is a useful approach to display the epidemiology and costs of MS. Claims data are reliable, cover a large population, and are widely used in epidemiological research. ${ }^{17}$

The aim of the present study is to assess actual prevalence, incidence, and costs of MS in Switzerland using claims data from one of the largest health insurances in Switzerland covering about $13 \%$ of the Swiss population (ca. 1.2 million persons with basic mandatory health insurance).

\section{Methods}

\section{Study population and context of the study}

Health insurance is mandatory in Switzerland, and the basic benefit package is the same in the entire country. The present study included health insurance claims from $\sim 1.2$ million adult persons aged 19 years or older residing in Switzerland who were enrolled with the Helsana Group. Data for the years 2011-2015 were used. All Swiss residents need to contract basic health insurance on a private market of health insurance, which is regulated by federal bodies. In order to protect those with poor health, health insurers are obliged to offer basic insurance to everyone and to charge the same premium to every individual irrespective of age or health status. Basic health insurance includes all outpatient or hospital medical treatment deemed appropriate, medically effective, and costeffective. Supplementary hospital insurance in Switzerland covers further comfort of a semiprivate or private ward or treatment in another canton for personal reasons. ${ }^{18}$ The insured person pays a share of the cost of health care in the form of an annual deductible cost (called a "franchise") ranging from 300 to a maximum of 2,500 CHF as selected by the insured person and a charge of $10 \%$ of the costs up to $700 \mathrm{CHF}$ per year. Currently, there are 57 insurance companies providing basic health coverage in Switzerland, and they offer a range of different premiums and types of health plans from which Swiss residents are free to choose. ${ }^{18,19}$ Managed care models are alternative insurance models for mandatory health insurance under which the insured persons agree to always first consult a specific type of health-care provider (ie, a group practice, a fixed family doctor, or a telemedicine center). ${ }^{18,20}$

\section{Identification of patients with MS}

Health insurance claims data in Switzerland do not include diagnoses from the ambulatory sector. We, therefore, used the WHO Anatomical Therapeutic Chemical (ATC) classification system for drugs to identify patients with MS. ${ }^{21}$ Long-term care (including prescription of medication therapy of MS) is done predominantly in the outpatient sector. Thus, this identification process guarantees approximately full capturing of all MS patients receiving drug treatment.

One or more treatments with one of the following drugs were used for identification of MS patients (Table 1).

Table I List of drugs used for identification of MS patients

\begin{tabular}{|c|c|c|c|}
\hline ATC code & Brand name & Active agent & Substance class \\
\hline L0IXC02 & Mabthera & Rituximab & Monoclonal antibody \\
\hline L03AB07 & Avonex & Interferon beta-la & Interferon \\
\hline L03AB07 & Rebif & Interferon beta-la & Interferon \\
\hline L03AB08 & Betaferon & Interferon beta-Ib & Interferon \\
\hline L03ABI3 & Plegridy & Peginterferon beta-la & Interferon \\
\hline L03AXI3 & Copaxone & Glatiramer acetate & Other immunostimulants \\
\hline L04AA23 & Tysabri & Natalizumab & Selective immunosuppressants \\
\hline L04AA27 & Gilenya & Fingolimod & Selective immunosuppressants \\
\hline L04AA3I & Aubagio & Teriflunomide & Selective immunosuppressants \\
\hline L04AA34 & Lemtrada & Alemtuzumab & Selective immunosuppressants \\
\hline N07XX09 & Tecfidera & Dimethyl fumarate & Other nervous system drugs \\
\hline
\end{tabular}

Abbreviations: ATC, Anatomical Therapeutic Chemical; MS, multiple sclerosis. 
The use of rituximab is off-label for MS, and alemtuzumab was off-label until January 2015. According to the Swiss Federal Health Insurance Ordinance, off-label use has to be approved by a medical examiner of basic mandatory health insurance. So, for these two drugs, indication of therapy is documented in the health insurance claims. We included only those cases in which rituximab and alemtuzumab were unambiguously used for the treatment of MS.

\section{Sociodemographic variables, morbidity, and mortality}

Available population characteristics included gender, age, language, area, and type of insurance coverage (managed care model, deductible class, etc.), and the presence of chronic condition using pharmaceutical cost groups (PCG). If medical diagnosis information is missing in the available data set, PCGs are established individual markers for selected chronic conditions. ${ }^{22}$ All-cause mortality of the study sample was recorded.

\section{Cost data}

Direct medical costs were derived from the perspective of Swiss basic mandatory health insurance. The database also contained information on all reimbursed invoices covering all settings of outpatient and inpatient care and nursing care. Since the recorded insurance claims cover almost all healthcare invoices, the data achieve a high degree of completeness. Annual total direct medical costs were obtained from providers' claims and defined as the total payments made by the mandatory health insurance for outpatient and inpatient services per patient per year. Costs from the outpatient setting comprised payments for office-based physician visits, hospital outpatient visits, paramedical visits, medications, laboratory tests, and medical devices. Inpatient costs covered payments for hospital treatments, rehabilitation, nursing home, and emergency transport services. Inpatient costs also cover the cost of medications, laboratory and medical services during the inpatient episode. Costs are given in $\mathrm{CHF}$ and are not adjusted for inflation during the observation period.

\section{Statistical analysis}

We calculated annual MS prevalence for 2011 to 2015 by dividing the number of patients with MS by all insured persons in the sample in the same year. In order to determine the incidence of MS in 2015, the number of newly identified cases with MS divided by the study population which is free of MS medication at the beginning of the year was calculated. We classified patients as incident cases if they were identi- fied as MS patients in 2015 and had a minimum MS-free period of 2 years in the previous years. In order to achieve representative estimates for Switzerland, all measures of prevalence, incidence, cost, and mortality were projected to the total population of Switzerland. This projection was done by increasing the number of persons and cost by the market share of Helsana for every group defined by age group, gender, and canton of residence. Cost of illness for MS was estimated using multivariate regression analysis. Due to the data being highly skewed to the right, a generalized linear model (glm) was chosen with log-link and gammatype variance structure. Only patients with positive medical costs were included in the model. As covariates, age group, sex, indicator for deceased, deductible class, managed care plan, accident coverage, supplementary inpatient insurance, and canton of residence were used. The model was fitted to the 2015 data. To measure the cost of illness, the marginal effects for each MS patient were calculated and averaged. First, the mean expected values for the MS patients were calculated and then the mean expected values for the MS patients treating them as non-MS patients were subtracted. This procedure was performed by bootstrapping for 1,000 samples of 1,000 individuals each from the population of the MS patients selected randomly with replacement. These marginal effects were calculated for the total costs and the total medication costs. The results indicated are the $2.5 \%$ percentile, the mean, and the $97.5 \%$ percentile of these 1,000 cost differences. All statistical analyses were performed using $\mathrm{R}$, version 3.2.0.

\section{Ethical approval}

The analysis complied with the Swiss Federal Law on data protection. All data were anonymized and de-identified prior to the performed analysis. According to the national ethical and legal regulation, an ethical approval was not needed because the data were retrospective, preexisting, and deidentified. Since data was anonymized, no consent of patients was required. Basic health insurance data in Switzerland is not publicly available.

\section{Results}

Our study population included about 940,000 subjects in each of the five investigated years comprising about 1,410 MS patients per year (detailed numbers of the study samples are shown in Table 2).

Characteristics of patients with MS in comparison with persons without MS are shown in Table 3. MS patients differed in all investigated socioeconomic variables. They were about 6 years younger (45.5 versus 51.8 years), more frequently 
Table 2 Sample size per year: persons with basic mandatory health insurance enrolled with the Helsana group

\begin{tabular}{lll}
\hline Year & Sample (N) & MS patients $(\mathbf{N})$ \\
\hline 2011 & 925,003 & 1,262 \\
2012 & 944,621 & 1,354 \\
2013 & 947,723 & 1,338 \\
2014 & 940,086 & 1,494 \\
2015 & 943,639 & 1,606 \\
\hline
\end{tabular}

Abbreviation: MS, multiple sclerosis.

female $(72.9 \%$ versus $52.5 \%)$, had more frequently a low annual deductible (94.6\% versus $67.9 \%$ ), were less frequently enrolled in a managed care health plan $(48.4 \%$ versus $59.1 \%)$, had less frequently accident coverage (50.3\% versus
$53.1 \%)$ and supplementary inpatient insurance (15.3\% versus $18.2 \%$ ). MS patients also differed in terms of clinical characteristics: MS patients suffered from more chronic conditions (as measured using PCGs) (2 versus 1.3) and used more different medications (10.8 versus 6.7). However, MS patients were less likely to die during the investigated insurance years $(0.3 \%$ versus $1.3 \%)$. The presence of a severe disease also reflects in higher health service utilization in MS patients as compared to non-MS persons. This is most obvious in medication cost to basic health insurance: MS patients had about 20-fold higher total medication costs (21,023 versus 1,048 CHF) and 8-fold higher outpatient

Table 3 Socioeconomic, clinical, and health utilization characteristics of the study population for persons with and without MS (year 2015)

\begin{tabular}{|c|c|c|c|c|c|}
\hline Characteristic & Measure & MS patients & no MS & Total & p-value \\
\hline \multirow[t]{2}{*}{ Age (years) } & n (\%) & $\mathrm{I}, 606(0.2)$ & $942,033(99.8)$ & $943,639(100)$ & \\
\hline & mean (median) & $45.5(46)$ & $5 I .8(5 I)$ & $5 I .8(5 \mathrm{I})$ & $<0.00 \mathrm{I}$ \\
\hline Age group: 19-25 & n (\%) & $72(4.5)$ & $89,567(9.5)$ & $89,639(9.5)$ & $<0.00 \mathrm{I}$ \\
\hline $26-30$ & n (\%) & $117(7.3)$ & $64,042(6.8)$ & $64,159(6.8)$ & \\
\hline $31-35$ & n (\%) & $197(12.3)$ & 74,756 (7.9) & 74,953 (7.9) & \\
\hline $36-40$ & n (\%) & $203(12.6)$ & $76,922(8.2)$ & $77,125(8.2)$ & \\
\hline $4 I-45$ & n (\%) & $213(13.3)$ & 76,807 (8.2) & $77,020(8.2)$ & \\
\hline $46-50$ & n (\%) & $263(16.4)$ & $81,874(8.7)$ & $82,137(8.7)$ & \\
\hline $5 I-55$ & n (\%) & $208(13.0)$ & 80,97। (8.6) & $81,179(8.6)$ & \\
\hline $56-60$ & n (\%) & $136(8.5)$ & $73,440(7.8)$ & $73,576(7.8)$ & \\
\hline $6 I-65$ & n (\%) & $99(6.2)$ & $68,397(7.3)$ & $68,496(7.3)$ & \\
\hline $66-70$ & n (\%) & $57(3.5)$ & $67,796(7.2)$ & 67,853 (7.2) & \\
\hline $7 I-75$ & n (\%) & $25(1.6)$ & $60,260(6.4)$ & $60,285(6.4)$ & \\
\hline $76-80$ & n (\%) & $14(0.9)$ & $48,479(5.1)$ & $48,493(5.1)$ & \\
\hline $8 I-85$ & n (\%) & $I(0.1)$ & 39,50 I (4.2) & $39,502(4.2)$ & \\
\hline $86-90$ & n (\%) & $\mathrm{I}(0 . \mathrm{I})$ & $25,520(2.7)$ & $25,52 \mid(2.7)$ & \\
\hline $91-\ldots$ & n (\%) & $0(0.0)$ & $|3,70|(1.5)$ & $|3,70|(\mid .5)$ & \\
\hline Female & n (\%) & I, I 70 (72.9) & $494,508(52.5)$ & $495,678(52.5)$ & $<0.00 \mathrm{I}$ \\
\hline Deductible (CHF) & Mean (median) & $40 I(300)$ & $879(300)$ & $878(300)$ & $<0.00$ I \\
\hline Low deductible ${ }^{a}$ & n (\%) & $1,519(94.6)$ & $639,544(67.9)$ & $641,063(67.9)$ & $<0.00 \mathrm{I}$ \\
\hline Managed care plan & n (\%) & $777(48.4)$ & $556,543(59.1)$ & $557,320(59.1)$ & $<0.00$ I \\
\hline Accident coverage & n (\%) & $808(50.3)$ & $499,799(53.1)$ & $500,607(53.1)$ & 0.030 \\
\hline Suppl inpatient insurance coverage "yes" & n (\%) & $245(15.3)$ & $17 \mid, 417(18.2)$ & $171,662(18.2)$ & 0.003 \\
\hline No of PCGs & Mean (median) & $2(2)$ & $1.3(1)$ & $1.3(1)$ & $<0.00 \mathrm{I}$ \\
\hline No of different ATC & Mean (median) & $10.8(9)$ & $6.7(4)$ & $6.7(4)$ & $<0.00$ I \\
\hline Deceased & n (\%) & $5(0.3)$ & $12,265(1.3)$ & $12,270(1.3)$ & $<0.00 \mathrm{I}$ \\
\hline Cost of MS medication & Mean (median) & $19,609(20,326)$ & $0(0)$ & $33(0)$ & $<0.00 \mathrm{I}$ \\
\hline Cost of total medication & Mean (median) & $21,023(20,930)$ & $\mathrm{I}, 048(205)$ & $\mathrm{I}, 082(206)$ & $<0.001$ \\
\hline Outpatient cost & Mean (median) & $27,459(26,509)$ & $3,452(1,372)$ & $3,493(1,378)$ & $<0.001$ \\
\hline Inpatient cost & Mean (median) & $\mathrm{I}, 486(0)$ & $1,513(0)$ & $1,5 \mid 3(0)$ & 0.050 \\
\hline Total cost & Mean (median) & $28,945(27,269)$ & $4,965(I, 466)$ & $5,006(1,472)$ & $<0.00 \mathrm{I}$ \\
\hline No of GP visits & Mean (median) & $5.4(4)$ & $3.7(2)$ & $3.7(2)$ & $<0.00 \mathrm{I}$ \\
\hline No of specialist visits & Mean (median) & $7.6(5)$ & $3.4(1)$ & $3.4(1)$ & $<0.00$ I \\
\hline No of hospital outpatient visits & Mean (median) & $6.8(3)$ & $2.3(0)$ & $2.3(0)$ & $<0.00 \mathrm{I}$ \\
\hline Inpatient length of stay & Mean (median) & $1.4(0)$ & $1.6(0)$ & $1.6(0)$ & 0.332 \\
\hline No of hospitalization episodes & Mean (median) & $0.2(0)$ & $0.2(0)$ & $0.2(0)$ & 0.416 \\
\hline
\end{tabular}

Note: ${ }^{a} \leq 500 \mathrm{CHF}$ per year.

Abbreviations: CHF, Swiss Francs; GP, general practitioner; MS, multiple sclerosis; PCGs, pharmaceutical cost groups; ATC, Anatomical Therapeutic Chemical; Suppl, supplementary. 
Table 4 Prevalence of MS (20I I-20I5), stratified by age group and sex extrapolated to the total population of Switzerland

\begin{tabular}{|c|c|c|c|c|c|c|c|c|c|c|c|}
\hline \multirow[t]{2}{*}{ Sex } & \multirow{2}{*}{$\begin{array}{l}\text { Age } \\
\text { group }\end{array}$} & \multicolumn{2}{|l|}{2011} & \multicolumn{2}{|l|}{2012} & \multicolumn{2}{|l|}{2013} & \multicolumn{2}{|l|}{2014} & \multicolumn{2}{|l|}{2015} \\
\hline & & $\begin{array}{l}\text { Prevalence } \\
\text { per } 100,000\end{array}$ & $95 \% \mathrm{Cl}$ & $\begin{array}{l}\text { Prevalence } \\
\text { per } 100,000\end{array}$ & $95 \% \mathrm{Cl}$ & $\begin{array}{l}\text { Prevalence } \\
\text { per } 100,000\end{array}$ & $95 \% \mathrm{Cl}$ & $\begin{array}{l}\text { Prevalence } \\
\text { per } 100,000\end{array}$ & $95 \% \mathrm{Cl}$ & $\begin{array}{l}\text { Prevalence } \\
\text { per } 100,000\end{array}$ & $95 \% \mathrm{Cl}$ \\
\hline Male & $19-40$ & 110 & $90-120$ & 100 & $80-120$ & 90 & $80-110$ & 100 & $80-120$ & 100 & $80-120$ \\
\hline Female & $19-40$ & 220 & $200-250$ & 230 & $210-260$ & 240 & $210-260$ & 260 & $240-290$ & 280 & $250-300$ \\
\hline Male & $4 I-65$ & 120 & $100-130$ & 120 & $100-140$ & 120 & $110-140$ & 140 & $120-160$ & 140 & $120-160$ \\
\hline Female & $4 I-65$ & 290 & $270-320$ & 310 & $280-330$ & 300 & $270-330$ & 330 & $310-360$ & 370 & $340-400$ \\
\hline Male & $\geq 66$ & 20 & $10-30$ & 20 & $10-20$ & 20 & $10-20$ & 20 & $10-30$ & 20 & $10-30$ \\
\hline Female & $\geq 66$ & 40 & $30-50$ & 40 & $30-50$ & 40 & $30-50$ & 60 & $40-70$ & 60 & $40-70$ \\
\hline Total & & 150 & $140-160$ & 160 & $150-170$ & 160 & $150-170$ & 180 & $\mid 70-180$ & 190 & $180-190$ \\
\hline
\end{tabular}

Abbreviation: MS, multiple sclerosis.

costs as compared to non-MS persons (27,459 versus 3,452 $\mathrm{CHF})$. Consistently, the number of visits with general practitioners (GPs; 5.4 versus 3.7), specialists (7.6 versus 3.4), and outpatient hospital visits (6.8 versus 2.3 ) was higher in MS patients. In contrast, these differences were not present for the inpatient sector: inpatient cost, inpatient length of stay, and number of inpatient stays did not statistically significantly differ. The pattern of differences was similar for the years 2011-2015.

Table 4 shows the overall prevalence of MS of 150 per 100,000 (estimate for 2011) to 190 per 100,000 (estimate for 2015) which translates to 10,000 (estimate for 2011) to 12,600 individuals with MS in Switzerland (estimate for 2015). Our results show a slight but continuous increase in prevalence of MS from 2011 to 2015. The incidence of MS was 16 per 100,000 (95\% CI: 13-19 per 100,000) which means that 1,100 individuals (95\% CI: 910-1,280) receive a diagnosis of MS per year in Switzerland (Table 5).

The crude mortality rate of the MS patients was very low and ranged from $0 \%$ (estimate for 2012 when no deceased MS patient was observed) to $0.248 \%$ (estimate for 2014) (Table 6). The corresponding confidence intervals range from $0 \%$ to $0.484 \%$. The corresponding crude rates for non-MS

Table 5 Incidence of MS (2015), stratified by age group and sex, extrapolated to the total population of Switzerland

\begin{tabular}{|c|c|c|c|}
\hline \multirow[t]{2}{*}{ Sex } & \multirow{2}{*}{$\begin{array}{l}\text { Age } \\
\text { group }\end{array}$} & \multicolumn{2}{|l|}{2015} \\
\hline & & $\begin{array}{l}\text { Incidence } \\
\text { per } 100,000\end{array}$ & $95 \% \mathrm{Cl}$ \\
\hline Male & $19-40$ & 10 & $5-14$ \\
\hline Female & $19-40$ & 38 & $27-48$ \\
\hline Male & $4 I-65$ & 8 & $4-11$ \\
\hline Female & $4 I-65$ & 28 & $20-35$ \\
\hline Male & $\geq 66$ & 1 & $0-2$ \\
\hline Female & $\geq 66$ & 1 & $0-1$ \\
\hline Total & & 16 & $13-19$ \\
\hline
\end{tabular}

Abbreviation: MS, multiple sclerosis. patients, extrapolated to the general population of Switzerland, were about four times higher than those for MS patients.

Extrapolated costs for MS medication in Switzerland oscillated around 19,000 CHF per year (Table 7). In consequence, mean overall costs for medication is about 24 times higher in MS patients as compared to non-MS persons with a difference of about 21,000 CHF per year (Table 8). Consistently, there were substantial differences in total health-care costs between MS patients and non-MS persons with total health-care costs being about seven times higher in MS patients. The difference ranged between 22,700 (estimate for 2011) and 26,000 (estimate for 2012) without a trend for increase over the investigated time period (Table 9).

The estimates of direct cost for MS derived from multivariate regression analysis for the year 2015 were 26,960 CHF (95\% CI: 26,170-27,800) per person per year for cost of medication and 26,710 CHF (95\% CI: 26,100-27,300) for total health-care costs when controlling for various confounders. CIs of both estimates overlapped indicating that they did not statistically significantly differ.

\section{Discussion}

This study provides current estimates of prevalence, incidence, mortality, and cost of MS in Switzerland. MS is a rare disease affecting 10,000-15,000 persons in Switzerland. It reveals that medication therapy for MS is the major part of

Table 6 Mortality of persons with and without MS in \% (201 I20I5), extrapolated to the total population of Switzerland

\begin{tabular}{lllll}
\hline Year & Non-MS & $\mathbf{9 5 \%} \mathbf{C l}$ & MS & $\mathbf{9 5 \%} \mathbf{C l}$ \\
\hline $201 \mathrm{I}$ & $\mathrm{I} .014$ & $0.996-1.032$ & 0.230 & $0.016-0.443$ \\
2012 & $\mathrm{I} .018$ & $1.000-1.036$ & 0.000 & $0.000-0.000$ \\
2013 & $\mathrm{I} .015$ & $0.998-1.033$ & 0.109 & $0.000-0.250$ \\
2014 & $0.97 \mathrm{I}$ & $0.954-0.989$ & 0.248 & $0.012-0.484$ \\
2015 & 1.023 & $1.006-1.041$ & 0.245 & $0.045-0.445$ \\
\hline
\end{tabular}

Abbreviation: MS, multiple sclerosis. 
Table 7 Mean annual costs of MS medication of basic health insurance (20II-20I5) in Swiss Francs per person per year, extrapolated to the total population of Switzerland

\begin{tabular}{lll}
\hline Year & Mean costs & $\mathbf{9 5 \%} \mathbf{C l}$ \\
\hline 2011 & 20,400 & $19,900-20,900$ \\
2012 & 19,700 & $19,200-20,100$ \\
2013 & 19,800 & $19,300-20,200$ \\
2014 & 18,500 & $18,100-18,900$ \\
2015 & 19,600 & $19,300-20,000$ \\
\hline
\end{tabular}

Abbreviation: MS, multiple sclerosis.

health-care costs in MS patients, and cost of illness for basic mandatory health insurance can almost entirely be explained by cost of MS medication.

Kingwell et al ${ }^{14}$ systematically reviewed the incidence and prevalence of MS in Europe. They found a large variation in prevalence ranging from 15 cases $/ 100,000^{23,24}$ to 230 cases $/ 100,000 .{ }^{25}$ They criticized that the identified studies lacked standardization related to case definition, and they concluded that further national-level studies were needed, especially when considering that prevalence is closely related to geographic, ethnic, and genetic factors. ${ }^{6}$ However, the prevalence estimate of about 160 cases/100,000 identified in the present study is plausible and ranks in the midfield of the prevalence estimates extracted from 123 studies. Another estimate of currently 12,500 persons with MS living in Switzerland is perfectly in line with our results. ${ }^{15}$

The preceding prevalence study by Beer and Kesselring found a prevalence of $110 \mathrm{MS}$ cases/100,000 inhabitants in Switzerland in 1994. ${ }^{16}$ The MS Barometer, a report of comparative MS data provided by European national MS societies organized as "European Multiple Sclerosis Platform" reports for Switzerland a prevalence of MS of 105/100,000 for the year 2009 and of 148/100,000 for the year $2011 .{ }^{26}$ Our study resulted in an estimate of 150/100,000 for 2011 and of 190/100,000 for 2015. Even if there is some imprecision related to these estimates, there is a clear trend indicating an increase in MS prevalence in Switzerland. This conclusion is supported by the fact that the prevalence estimates are derived from different data sources which increases trust in the generalizability of the results. However, the question is whether this increase in prevalence is real. ${ }^{27}$ For example, the increased availability of magnetic resonance imaging and, consequently, improved diagnosis of MS may explain an apparent increase in prevalence. ${ }^{28}$ Specifically, the time delay between onset and diagnosis of MS has probably declined, and the diagnostic awareness among physicians and patients has increased. ${ }^{29}$ Thus, the rise in prevalence is - at least in part a consequence of the underestimated prevalence reported previously. Otherwise, the growth in prevalence may be due to an improved probability of survival. ${ }^{30,31}$ In addition, many potential etiological factors such as infection, immunizations, physical and emotional stressors, climate, diet, and occupational exposures have been suspected to trigger the autoimmune disease among susceptible people. ${ }^{32-35}$

However, none of these hypotheses are fully validated, and it is unclear, whether these factors have changed in the past years in Switzerland. Certainly, this increase of MS has been observed internationally. ${ }^{14,36}$ Future epidemiological studies are needed to search for potentially preventable causes of MS.

Recently, the Swiss MS Cohort has been established - a prospective observational study including $872 \mathrm{MS}$ patients from 7 large MS centers across Switzerland. This cohort study may help to investigate the mechanisms leading to disability and the long-term efficacy and safety of disease modifying drugs (DMDs) in MS. ${ }^{37}$ The cohort might also be helpful in identifying potential environmental risk factors relevant in Switzerland.

A recent survey supported by the European Platform of MS Societies (EMSP) investigated burden and costs of MS in Switzerland..$^{5}$ In this study, mean annual costs varied between 29,600 CHF for low disability scores, 66,800 CHF for moderate, and 110,800 CHF for high disability scores. However, these cost estimates also included various costs not covered by basic health insurance such as early retirement, work absence, informal care, or community services. Health-care costs varied between $19,421( \pm 15,616)$ and $34,910( \pm 53,040)$ $\mathrm{CHF}$, so that the estimates derived from the present study are

Table 8 Mean overall costs of basic health insurance for medication and difference between persons with and without MS in Swiss Francs (20II-20I5), extrapolated to the total population of Switzerland

\begin{tabular}{lllllll}
\hline Year & Non-MS & $\mathbf{9 5 \%} \mathbf{C l}$ & MS & $\mathbf{9 5 \%} \mathbf{C l}$ & Difference & $\mathbf{9 5 \%} \mathbf{C l}$ \\
\hline 2011 & 920 & $910-930$ & 23,000 & $22,300-23,700$ & 22,100 & $21,400-22,800$ \\
2012 & 950 & $940-960$ & 24,200 & $23,700-24,700$ & 23,200 & $22,700-23,800$ \\
2013 & 940 & $930-950$ & 21,900 & $21,500-22,400$ & 21,000 & $20,500-21,400$ \\
2014 & 950 & $940-960$ & 21,100 & $20,700-21,500$ & 20,100 & $19,700-20,500$ \\
2015 & 980 & $980-990$ & 21,100 & $20,700-21,500$ & 20,100 & $19,700-20,500$ \\
\hline
\end{tabular}

Abbreviation: MS, multiple sclerosis. 
Table 9 Mean overall health-care costs of basic health insurance (per person per year) and difference between persons with and without MS in Swiss Francs (20II-20I5), extrapolated to the total population of Switzerland

\begin{tabular}{lllllll}
\hline Year & Non-MS & $\mathbf{9 5} \% \mathbf{C l}$ & MS & $\mathbf{9 5 \%} \mathbf{C l}$ & Difference & $\mathbf{9 5 \%} \mathbf{C l}$ \\
\hline 2011 & 4,080 & $4,060-4,100$ & 26,800 & $26,000-27,600$ & 22,700 & $21,900-23,500$ \\
2012 & 4,240 & $4,220-4,260$ & 30,300 & $29,500-31,000$ & 26,000 & $25,300-26,800$ \\
2013 & 4,300 & $4,280-4,320$ & 29,700 & $28,900-30,400$ & 25,400 & $24,600-26,100$ \\
2014 & 4,440 & $4,410-4,460$ & 28,700 & $28,000-29,400$ & 24,300 & $23,600-24,900$ \\
2015 & 4,550 & $4,530-4,570$ & 28,800 & $28,200-29,400$ & 24,300 & $23,600-24,900$ \\
\hline
\end{tabular}

Abbreviation: MS, multiple sclerosis.

coherent. However, costs for medication in the EMSP study were somewhat lower (10,752-16,009 CHF). As the EMSP study was based on self-report, potential imprecision and recall bias may have contributed to the difference between those estimates and the results of the present study.

A recent systematic review collected 48 cost of illness studies in MS and found out that medications were the main cost drivers for MS patients with low disease severity, representing $29 \%-82 \%$ of all costs in this patient group. However, the main predictors of costs for groups with more advanced MS symptoms were production losses due to MS and informal care, accounting for $17 \%-67 \%$ of costs in those groups. ${ }^{9}$ Thus, there is a big difference in resource utilization at different stages of the disease. Disease modifying therapies are most appropriate at low severity, and the goal of treatment is to prevent progression. When disease progresses, costs associated with MS drugs decrease, and the pattern of expenditure changes. The comparability of the cost of illness estimate of the present study with figures derived from other healthcare settings is very limited as data are based on different structures of the reimbursement system, the insurance coverage, and the organization of health services.

Current clinical practice guidelines recommend medication therapy based on severity levels of the disease. However, to date, there is a lack of good quality head-to-head comparisons between the new oral immunotherapies, new monoclonal antibodies, and the established immunotherapies. ${ }^{38}$ Given the predominant role of medications for the use of resources in MS patients, the uncertainty related to comparative effectiveness of MS medications is striking. ${ }^{11}$

Different limitations need to be considered when interpreting the results of this study. Firstly, our study was based on reimbursement data from mandatory health insurance, and we were not able to include clinical information or information related to indirect costs and costs for informal care. However, routine data from basic mandatory health insurance depicts real-life management as it includes all diagnostic, therapeutic, and rehabilitative measures that have been reimbursed. Secondly, in the absence of ambulatory diagnostic information in our data set, we identified MS cases based on MS-specific medication. However, it is very unlikely that patients agree to take MS medication which is associated with severe adverse events such as activation of other autoimmune disorders, leukopenia, or bradycardia when there are no clear diagnostic criteria or severe suffering. ${ }^{39,40}$ Thirdly, we used data from a single health insurance, and results may differ across populations of different health insurances across Switzerland. However, we used data from one of the largest health insurances covering about $13 \%$ of the Swiss population from all parts of the country, and we extrapolated the results to the general population of Switzerland to account for differences in the market share different demographic subgroups. Fourthly, the present study adopts a purely unidimensional perspective as it focuses on the cost for basic mandatory health insurance. Other dimensions impacting cost of illness such as sickness absence, early retirement due to MS, or informal care were not considered as they are not part of the mandatory benefits package in Switzerland and can thus not be captured by basic mandatory health insurance. In addition, comparisons were made between persons with MS medication, used as an identifier of disease, and the population without MS medication. Comorbidities present in both groups were not adjusted for. Nevertheless, our study confirms the prominent role of MS medication for costs caused by the care for persons with MS.

The present study has implications for future research. Good quality evidence and clinical guidelines are needed to define criteria related to the selection of the most appropriate medication, required security checks such as regular blood cell counts or electrocardiogram, contraindications and practical guidance for change of treatment. Further evidence related to direct comparisons between active agents is needed including the medium- and long-term benefit and safety of immunotherapies and the comparative safety of different agents. ${ }^{10}$ It is the interest of both affected patients and premium payers that the high costs caused by the use of MS medications is strictly effective, safe, and efficient. 
The basis of these principles is transparency related to the burden of disease both on the individual and on the population level, and transparency related to costs and efficiency of care for MS.

\section{Acknowledgment}

Financial support for this study was provided by Biogen, Switzerland. We thank Biogen for supporting our study.

\section{Disclosure}

The authors report no conflicts of interest in this work.

\section{References}

1. Krieger SC, Cook K, De Nino S, Fletcher M. The topographical model of multiple sclerosis: A dynamic visualization of disease course. Neurol Neuroimmunol Neuroinflamm. 2016;3(5):e279.

2. Kobelt G, Berg J, Gannedahl M, Eriksson J, Thompson A, MS BOI Study Group. Cognition, fatigue and health related quality of life in patients with multiple sclerosis: results from a European-wide study. Poster presentation, ECTRIMS; 2016.

3. Grima DT, Torrance GW, Francis G, Rice G, Rosner AJ, Lafortune L. Cost and health related quality of life consequences of multiple sclerosis. Mult Scler. 2000;6(2):91-98.

4. Asche CV, Ho E, Chan B, Coyte PC. Economic consequences of multiple sclerosis for Canadians. Acta Neurol Scand. 1997;95(5):268-274.

5. Calabrese P, Kobelt G, Berg J, Capsa D, Eriksson J; European Multiple Sclerosis Platform. New insights into the burden and costs of multiple sclerosis in Europe: results for Switzerland. Mult Scler. 2017;23(2 Suppl):192-203.

6. Browne P, Chandraratna D, Angood C, et al. Atlas of Multiple Sclerosis 2013: a growing global problem with widespread inequity. Neurology. 2014;83(11):1022-1024.

7. Kobelt G, Berg J, Lindgren P, Gerfin A, Lutz J. Costs and quality of life of multiple sclerosis in Switzerland. Eur J Health Econ. 2006; 7(Suppl 2):S86-S95.

8. O'Connell K, Kelly SB, Fogarty E, et al. Economic costs associated with an MS relapse. Mult Scler Relat Disord. 2014;3(6):678-683.

9. Ernstsson O, Gyllensten H, Alexanderson K, Tinghög P, Friberg E, Norlund A. Cost of illness of multiple sclerosis - a systematic review. PLoS One. 2016;11(7):e0159129.

10. Comparative Clinical and Cost-Effectiveness of Drug Therapies for Relapsing-Remitting Multiple Sclerosis - Project Protocol [Internet]. Ottawa (ON): Canadian Agency for Drugs and Technologies in Health; 2012 Dec. (CADTH Therapeutic Review, No. 1.2A.) Available from: https://www.ncbi.nlm.nih.gov/books/NBK361336/. Accessed December 1, 2016.

11. Tramacere I, Del Giovane C, Salanti G, D’Amico R, Filippini G. Immunomodulators and immunosuppressants for relapsing-remitting multiple sclerosis: a network meta-analysis. Cochrane Database Syst Rev. 2015;(9):CD011381.

12. Freedman MS, Montalban X, Miller AE, et al. Comparing outcomes from clinical studies of oral disease-modifying therapies (dimethyl fumarate, fingolimod, and teriflunomide) in relapsing MS: Assessing absolute differences using a number needed to treat analysis. Mult Scler Relat Disord. 2016;10:204-212.

13. Helsana Group. Der Helsana Arzneimittel. [The Helsana medicine]. report 2015. Available from: http://www.helsana.ch/de/helsana-gruppe/ unternehmen/gesundheitswissenschaften/arzneimittelreport. German. Accessed December 1, 2016. German.

14. Kingwell E, Marriott JJ, Jetté N, et al. Incidence and prevalence of multiple sclerosis in Europe: a systematic review. BMC Neurol. 2013; 13:128.
15. European Multiple Sclerosis Platform. MS Barometer 2013. Available from: http://www.emsp.org/projects/ms-barometer/. Accessed December 1, 2016.

16. Beer S, Kesselring J. High prevalence of multiple sclerosis in Switzerland. Neuroepidemiology. 1994;13(1-2):14-18.

17. Huber CA, Schwenkglenks M, Rapold R, Reich O. Epidemiology and costs of diabetes mellitus in Switzerland: an analysis of health care claims data, 2006 and 2011. BMC Endocr Disord. 2014;14:44.

18. Blozik E, Signorell A, Reich O. How does hospitalization affect continuity of drug therapy: an exploratory study. Ther Clin Risk Manag. 2016;12:1277-1283.

19. Reich O, Wolffers F, Signorell A, Blozik E. Health care utilization and expenditures in persons receiving social assistance in 2012: evidence from Switzerland. Glob J Health Sci. 2014;7(4):1-11.

20. Reich O, Rapold R, Flatscher-Thöni M. An empirical investigation of the efficiency effects of integrated care models in Switzerland. Int $J$ Integr Care. 2012;12:e10.

21. WHO Collaborating Centre for Drug Statistics Methodology. ATC/ DDD Index. Available from: http://www.whocc.no/atc_ddd_index/. Accessed December 1, 2016.

22. Huber CA, Szucs TD, Rapold R, Reich O. Identifying patients with chronic conditions using pharmacy data in Switzerland: an updated mapping approach to the classification of medications. BMC Public Health. 2013;13:1030.

23. Grasso AA, Regio A, Marano P, et al. Epidemiological survey of multiple sclerosis in Catania city. Ital J Neurol Sci. 1992;13(4): 301-309.

24. Garcia JR, Rodriguez S, Sosa Henriquez M, et al. Prevalence of multiple sclerosis in Lanzarote (Canary Islands). Neurology. 1989;39(2 Pt 1): 265-267.

25. Binzer M, Forsgren L, Holmgren G, Drugge U, Fredrikson S. Familial clustering of multiple sclerosis in a northern Swedish rural district. J Neurol Neurosurg Psychiatry. 1994;57(4):497-499.

26. European Multiple Sclerosis Platform. MS Barometer; 2011. Available from: http://www.emsp.org/wp-content/uploads/2015/07/ MS_Barometer_2011.pdf/. Accessed December 1, 2016.

27. Benito-León J. Are the prevalence and incidence of multiple sclerosis changing? Neuroepidemiology. 2011;36(3):148-149.

28. Sarasoja T, Wikstrom J, Paltamaa J, Hakama M, Sumelahti ML: Occurrence of multiple sclerosis in central Finland: a regional and temporal comparison during 30 years. Acta Neurol Scand. 2004;110(5): 331-336.

29. Grytten N, Aarseth JH, Lunde HM, Myhr KM. A 60-year follow-up of the incidence and prevalence of multiple sclerosis in Hordaland County, Western Norway. J Neurol Neurosurg Psychiatry. 2016; 87(1):100-105.

30. Brønnum-Hansen H, Koch-Henriksen N, Stenager E. Trends in survival and cause of death in Danish patients with multiple sclerosis. Brain. 2004;127(Pt 4):844-850.

31. Kavaliunas A, Manouchehrinia A, Stawiarz L, et al. Importance of early treatment initiation in the clinical course of multiple sclerosis. Mult Scler. 2017;23(9):1233-1240.

32. Benito-León J, Pisa D, Alonso R, Calleja P, Díaz-Sánchez M, Carrasco L. Association between multiple sclerosis and Candida species: evidence from a case-control study. Eur J Clin Microbiol Infect Dis. 2010;29(9):1139-1145.

33. Pierrot-Deseilligny C, Souberbielle JC. Is hypovitaminosis D one of the environmental risk factors for multiple sclerosis? Brain. 2010;133(Pt 7): $1869-1888$.

34. Fleming JO, Cook TD. Multiple sclerosis and the hygiene hypothesis. Neurology. 2006;67:2085-2086.

35. Ramagopalan SV, Dobson R, Meier UC, Giovannoni G. Multiple sclerosis: risk factors, prodromes, and potential causal pathways. Lancet Neurol. 2010;9(7):727-739.

36. Makhani N, Morrow SA, Fisk J, et al. MS incidence and prevalence in Africa, Asia, Australia and New Zealand: a systematic review. Mult Scler Relat Disord. 2014;3(1):48-60. 
37. Disanto G, Benkert P, Lorscheider J, et al. The Swiss Multiple Sclerosis Cohort-Study (SMSC): a Prospective Swiss Wide Investigation of Key Phases in Disease Evolution and New Treatment Options. PLoS One. 2016;11(3):e0152347.

38. German Society of Neurology. Leitlinie: Diagnose und Therapie der Multiplen Sklerose. [Guideline: Diagnosis and therapy of multiple sclerosis]. Available from: http://www.dgn.org/leitlinien/2333-11-312012-diagnose-und-therapie-der-multiplen-sklerose. German. Accessed December 1, 2016. German.
39. Wingerchuk DM, Carter JL. Multiple sclerosis: current and emerging disease-modifying therapies and treatment strategies. Mayo Clin Proc. 2014;89(2):225-240.

40. Lublin F, Miller DH, Freedman MS, et al. Oral fingolimod in primary progressive multiple sclerosis (INFORMS): a phase 3, randomised, doubleblind, placebo-controlled trial. Lancet. 2016;387(10023):1075-1084.

Neuropsychiatric Disease and Treatment

\section{Publish your work in this journal}

Neuropsychiatric Disease and Treatment is an international, peerreviewed journal of clinical therapeutics and pharmacology focusing on concise rapid reporting of clinical or pre-clinical studies on a range of neuropsychiatric and neurological disorders. This journal is indexed on PubMed Central, the 'PsycINFO' database and CAS, and is the official journal of The International Neuropsychiatric Association (INA). The manuscript management system is completely online and includes a very quick and fair peer-review system, which is all easy to use. Visit http://www.dovepress.com/testimonials.php to read real quotes from published authors.

Submit your manuscript here: http://www.dovepress.com/neuropsychiatric-disease-and-treatment-journal 